\title{
Advanced techniques for the monitoring of pillar and excavation behaviour at a deep level massive mine
}

\author{
P.G. Andrews ${ }^{1}$, L. Rwodzi ${ }^{2}$, J. Ekkerd ${ }^{2}$, and N Ratshitaka ${ }^{2}$ \\ ${ }^{1}$ Gold Fields, Australia \\ 2Gold Fields, South Africa
}

\begin{abstract}
The mining methods used at South Deep started with conventional mining (pre-1998), which later evolved into mechanized mining with various layouts for drifting and benching, low-profile horizontal destressing with crush pillars and long hole stoping (LHS). The mining method was then changed during 2015-2016 to the current high profile destress with LHS. Pillars in the destress cuts are designed to yield and not pose a significant rock burst risk.
\end{abstract}

High profile development was initially conducted using smaller pillars $(4.5 \mathrm{~m} \times 10 \mathrm{~m}$ and $6 \mathrm{~m} \times 10 \mathrm{~m}$ ) which completely yielded however, as these were prone to excessive scaling and extensive rehabilitation requirements. Numerical modelling was conducted by Lilly, (2016), to optimise the destress pillar dimensions. The study concluded that a larger yield pillar is viable in the high profile destress cuts.

The new pillar design was still not proven in situ owing to lack of information regarding to yielding, closure rates, convergence and fracturing through the core as well as the transition between the old and new mining layout.

As a first approach, borehole camera surveys were conducted to assess the pillar conditions. Ground penetrating radar (GPR) technology was then used to determine fracturing around the yield pillars and where possible, the results where compared to the borehole camera surveys.

A Zeb Revo scanner was then used to obtain accurate closure and pillar yield performance. This data was used to calibrate actual vs model-predicted displacements and to calibrate numerical models, reconciling pillar and also pro-actively identify areas that were undergoing extensive deformation.

This paper will describe the outcome of the above-mentioned monitoring and reconciliation programmes and the interpretation of the results.

\section{INTRODUCTION}

The mining method at South Deep consists of two distinct phases. Initially, a $5.5 \mathrm{~m}$ high horizontal slice is mined through the targeted reef package. This phase is referred to as destressing as it reduces the major in situ stress component from around $70 \mathrm{MPa}$ to about $30 \mathrm{MPa}$, Watson (2014). Destressing the reef allows the second phase of mining of long hole stopes without the high rock stresses associated with mining at depths of $2700 \mathrm{~m}$ to $3300 \mathrm{~m}$, to proceed. Long hole stoping (LHS), is accessed from the destress excavations and is limited in size to $20 \mathrm{~m}$ in height and $60 \mathrm{~m}$ in length. These horizontal destress cuts are mined at $20 \mathrm{~m}$ vertical intervals. 
The mine is divided into six corridors with a maximum span of $180 \mathrm{~m}$. Each corridor is separated by a $60 \mathrm{~m}$ regional pillar (See Figure 1 and Figure 2). Where reef targets are thinner, between $5 \mathrm{~m}$ and $15 \mathrm{~m}$, drifting and benching is applied.
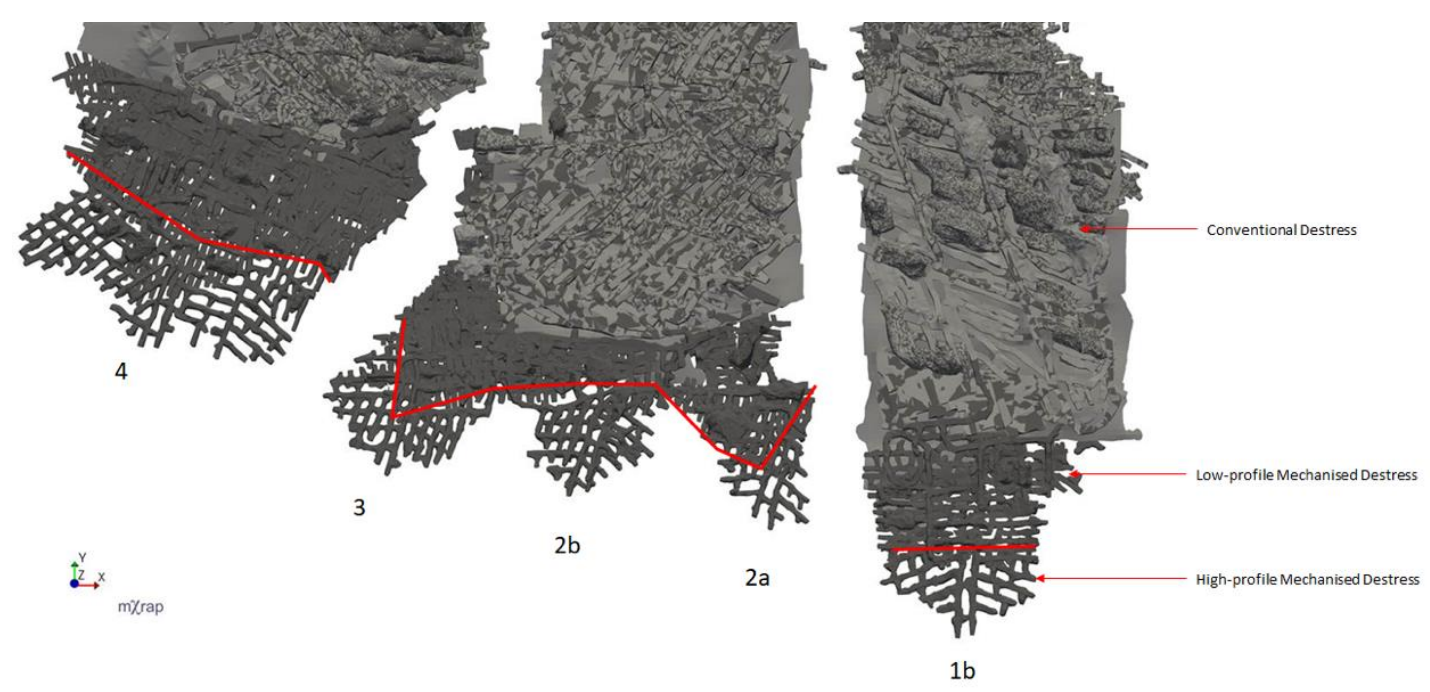

Figure 1. Various mining cuts and phases of mining at South Deep. Corridor 2B started off with $4.5 \mathrm{~m}$ wide by $10 \mathrm{~m}$ long pillars which were subsequently increased to $6 \mathrm{~m}$ wide by $10 \mathrm{~m}$ long pillars and then most recently 8 $m$ wide $x 20 \mathrm{~m}$ long pillars

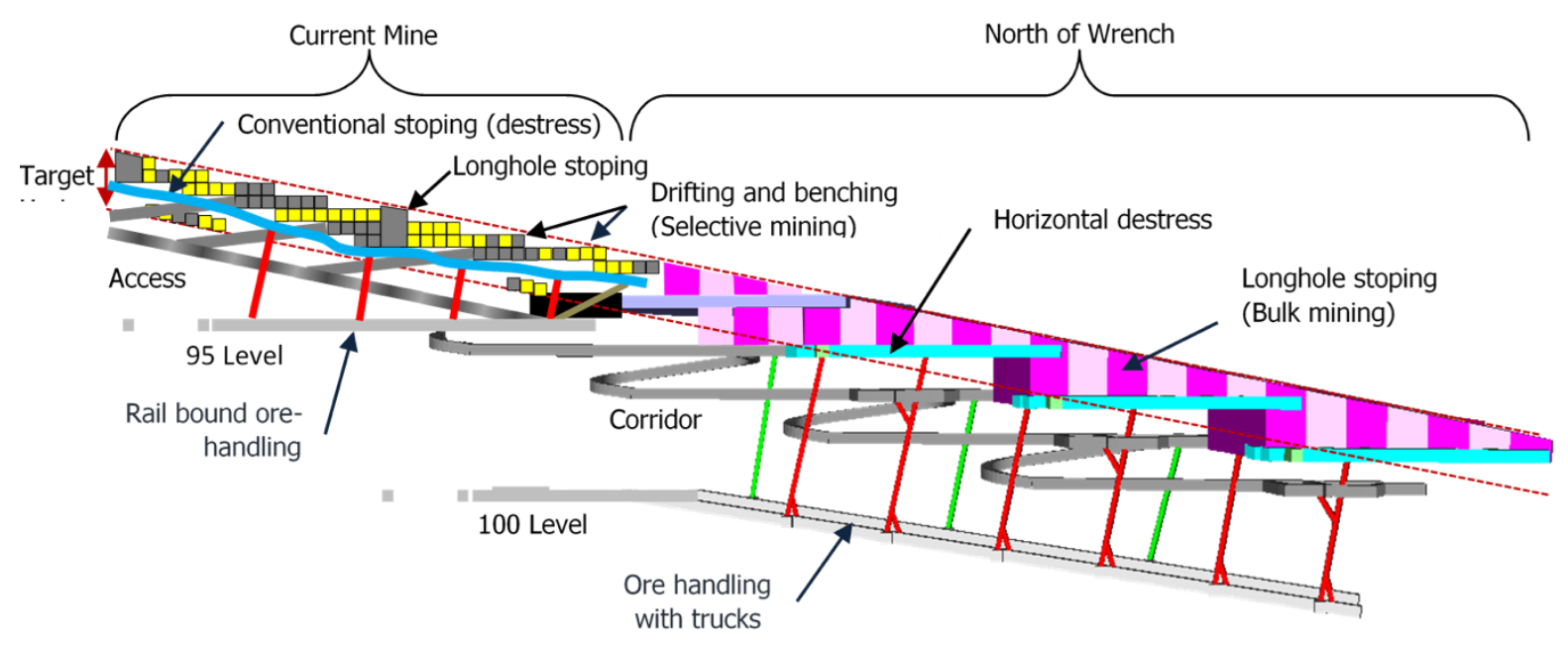

Figure 2. A 3D schematic illustration of South Deep gold mine showing all the mining

South Deep changed from partial conventional-mechanised mining to full trackless mechanised mining in 2008, Joughin et al (2011). The changeover to mechanised mining saw the introduction of bord and pillar mining using initially an apparent dip de-stressing method following dip of the reef which was then modified to a horizontal de-stressing method. The major advantage of the horizontal cut was that it allowed sharing of capital infrastructure (destress cut drives) between the destress cuts and stoping.

Initial layouts consisted of $10 \mathrm{~m}$ long $\times 1.5 \mathrm{~m}$ wide $\times 2.2 \mathrm{~m}$ high crush pillars, Watson et al (2014). This method is known as low profile stoping (LPS). The initially reduced extraction ratio and lower backfill demands resulted in improved productivity. As mining extended, the behaviour of the crush pillars was characterised by extensive fracturing and failure (See Figure 3). Consequently, in late 2013, the 
pillar dimensions were increased to $10 \mathrm{~m}$ long $\times 2.5 \mathrm{~m}$ wide $\times 2.2 \mathrm{~m}$ high. The crush pillars had variable capacities which still led to irregular closure and support deformation.
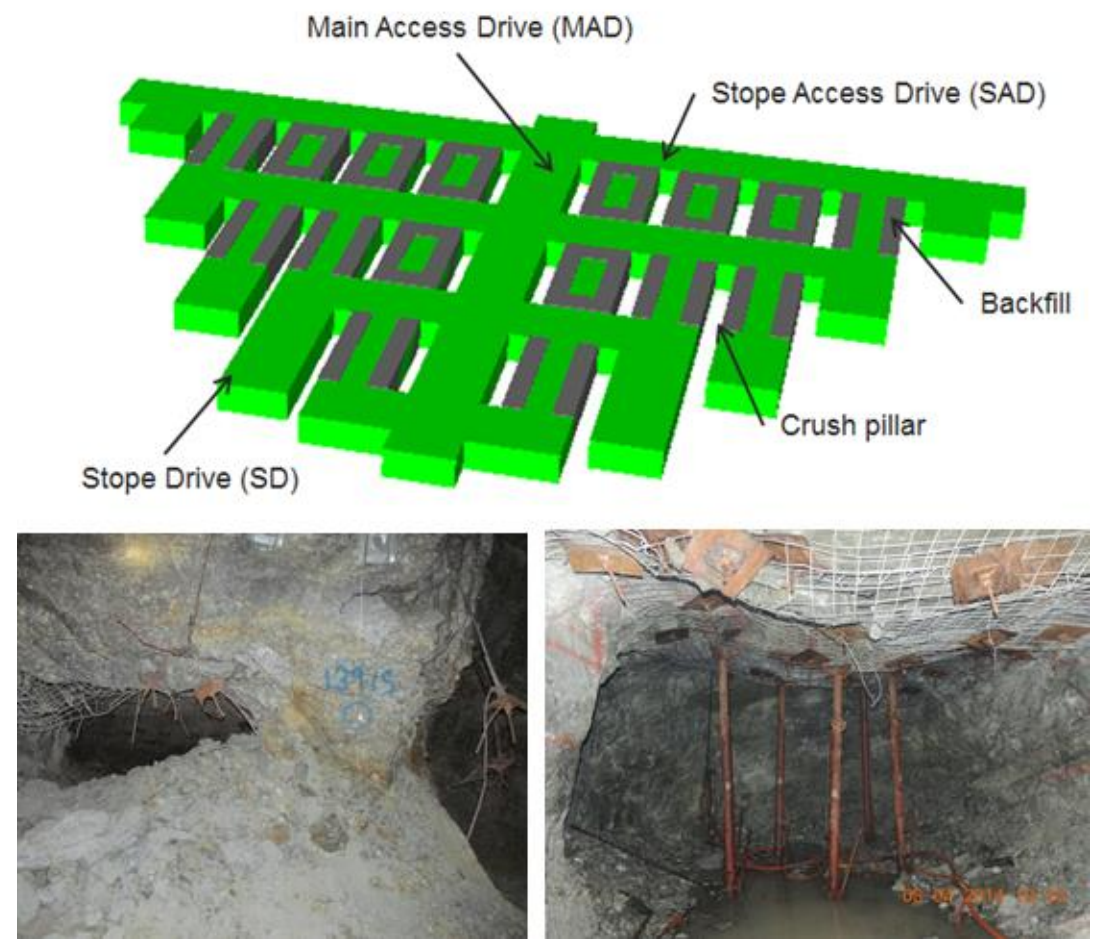

Figure 3. Low profile stoping layout, pillar and support conditions

Owing to very high closure rates when using the low profile destress method, the destress was converted to a high profile destress method with an increased pillar size in 2015, Lilley (2014). Future recommended horizontal destress development was to be done using larger destress pillars, starting at $4.5 \mathrm{~m}$ wide by $5.5 \mathrm{~m}$ high by $10 \mathrm{~m}$ long pillars.

During 2016, significant design improvements were made in both the destress cut design as well as the access design; the pillar dimensions were increased from $6 \mathrm{~m}$ wide $\times 10 \mathrm{~m}$ long, to $8 \mathrm{~m}$ wide $\times 20 \mathrm{~m}$ long to form yield pillars. Yield pillars are pillars which have a SF $>1$ or even SF equal to 1 when first formed, but then yield in a stable manner at stress levels near to peak strength, Ozbay et al (1995). The pillars are sized, often using empirical and observational approaches so that they do not store excessive strain energy and burst, but remain intact enough to maintain a residual strength. In practice, yield pillars are intact when formed and then weaken as the load on them increases beyond their load bearing capacity which causes them to yield.

The cut yield pillar design ( $8 \mathrm{~m}$ wide by $20 \mathrm{~m}$ long (See Figure 4), is based on the work of Lilley (2016) and the following was noted during the study:

- High closure is expected to damage the ground support and lead to extensive fracturing, leading to slabs spalling away from the pillar sidewalls. If the spalling is not controlled, then the pillars are likely to disintegrate, leading to span increases and then, possibly, the collapse of the main access drives (MADs) and strike access drives (SADs).

- Modelling forecasts very high levels of rock mass damage (See Figure 5). Pillars yield throughout and therefore cannot store energy and have very little risk of bursting. 


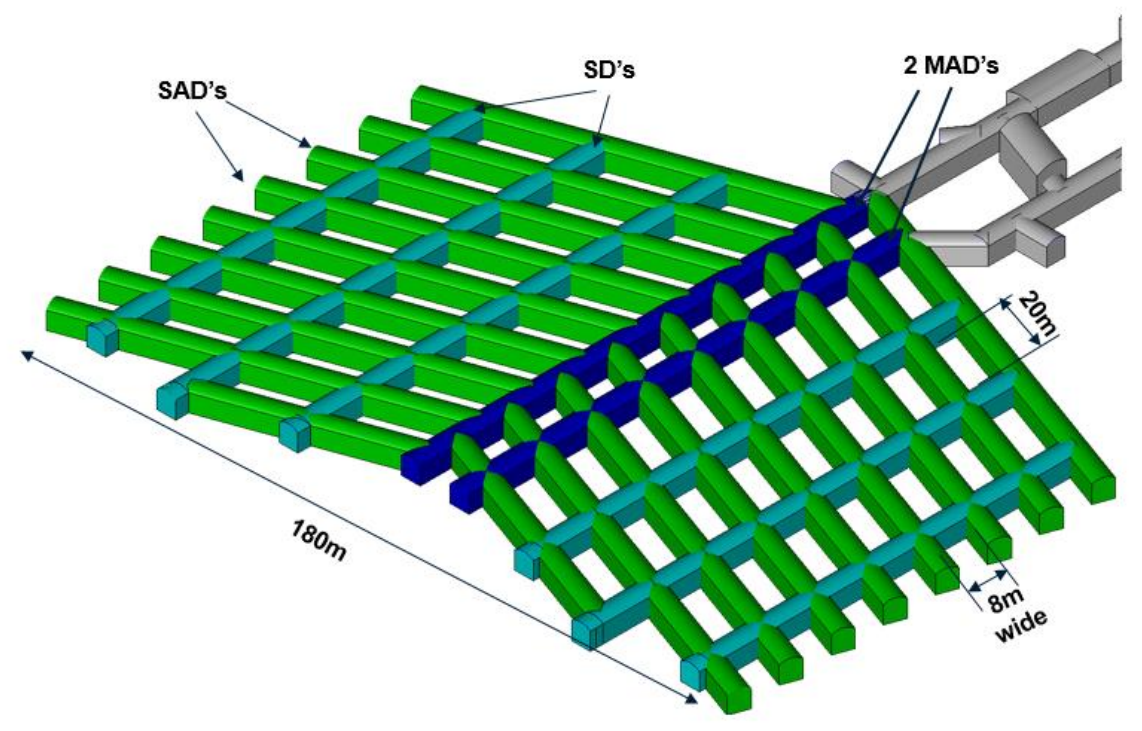

Figure 4. HPS layout with the $8 \mathrm{~m}$ wide $\times 20 \mathrm{~m}$ long rib pillars
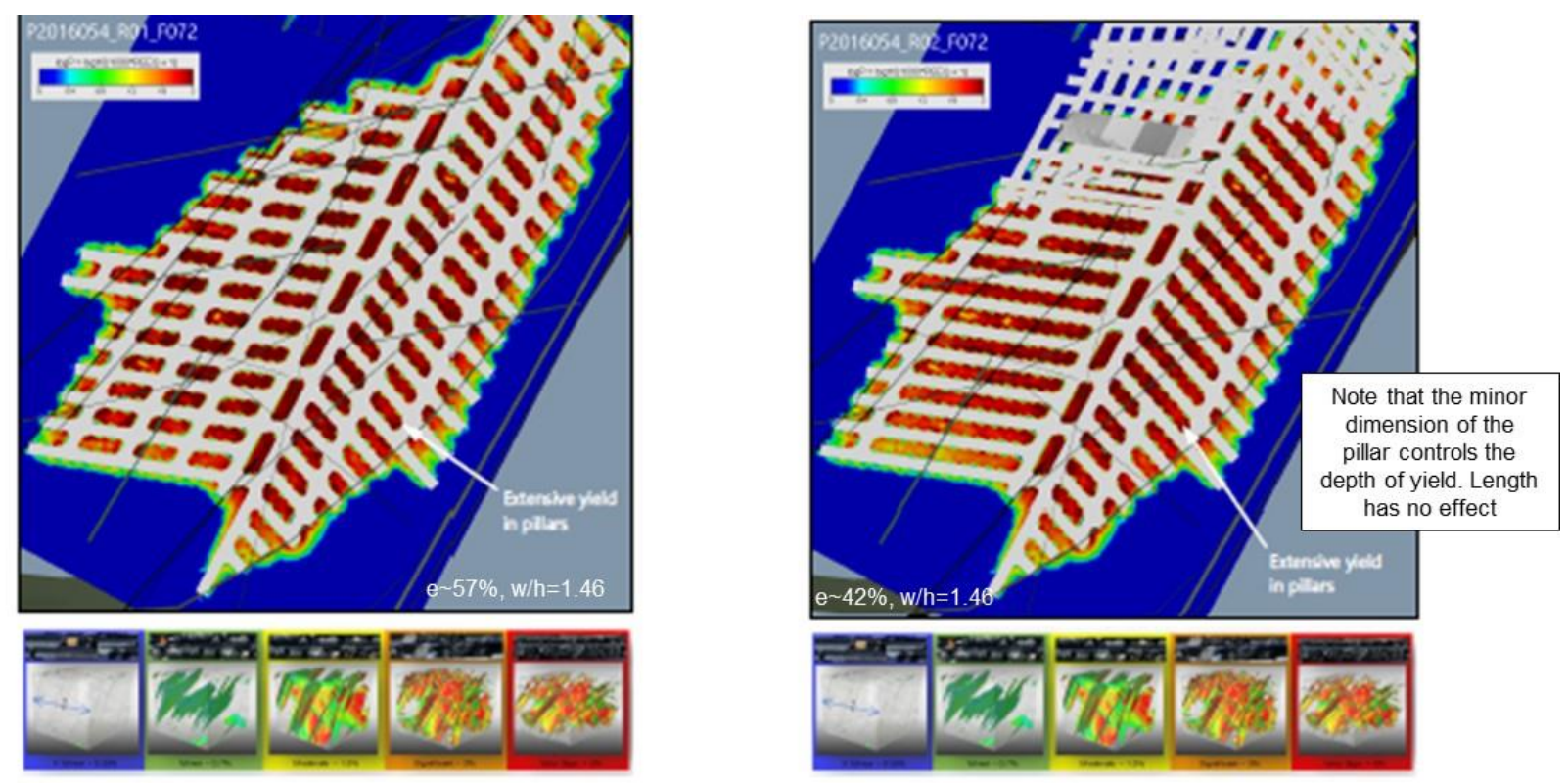

Figure 5. Lilley (2016) used the non-linear inelastic package finite element package ABAQUS to evaluate the performance of various high-profile mining pillar sizes. Rockmass damage is depicted for the $8 \mathrm{~m}$ long $x 20 \mathrm{~m}$ wide pillars is on the left and for $8 \mathrm{~m}$ wide by various length pillars on the right

\section{Pillar observations underground}

From underground observations, it was clear that the new $8 \mathrm{~m}$ wide $\times 20 \mathrm{~m}$ long pillars were extensively spalling and potentially yielding as modelled by Lilley (2016); however, no onsite calibration was done to confirm the amount and depth of damage in the pillars and the predicted closure in the mining cuts (See Figure 6). There was ongoing uncertainty as to what pillar size was the appropriate size to achieve controlled yielding without undergoing too much deformation or storing too much energy that could potentially lead to bursting (See Figure 7). 

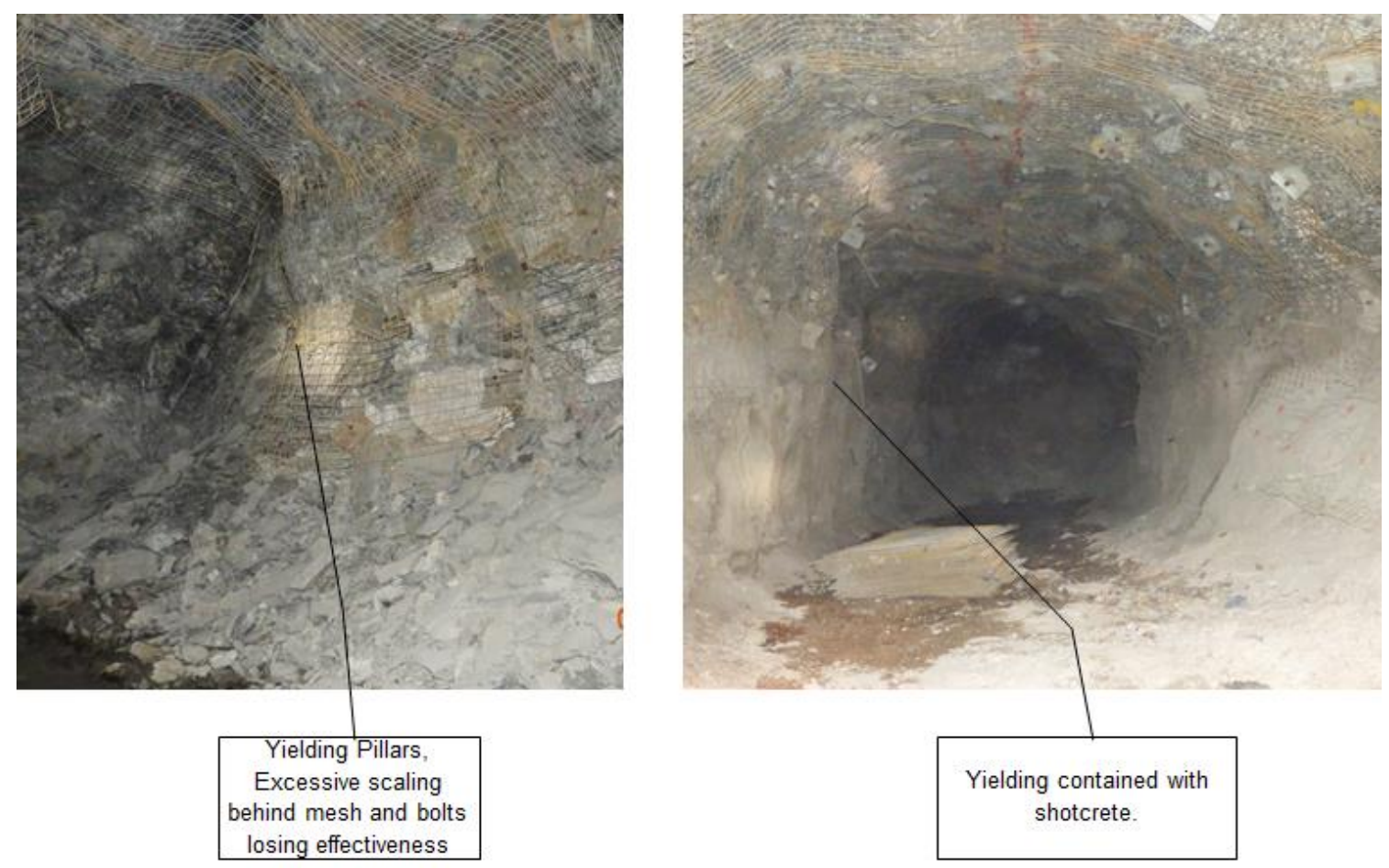

Figure $6.8 \mathrm{~m}$ wide $x 20 \mathrm{~m}$ long pillars pillar yielding and spalling behind the mesh

In 2018, a study of the new $8 \mathrm{~m}$ wide $\times 20 \mathrm{~m}$ long pillars was undertaken to understand pillar behaviour and performance. This was done using borehole camera monitoring, ground penetrating radar (GPR) and more recently, 3D laser deformation monitoring.

The paper deals primarily with the performance of the pillars in the new high-profile mechanised mining destress cuts, the monitoring approaches used at South Deep Mine and results from the pillar monitoring programme.

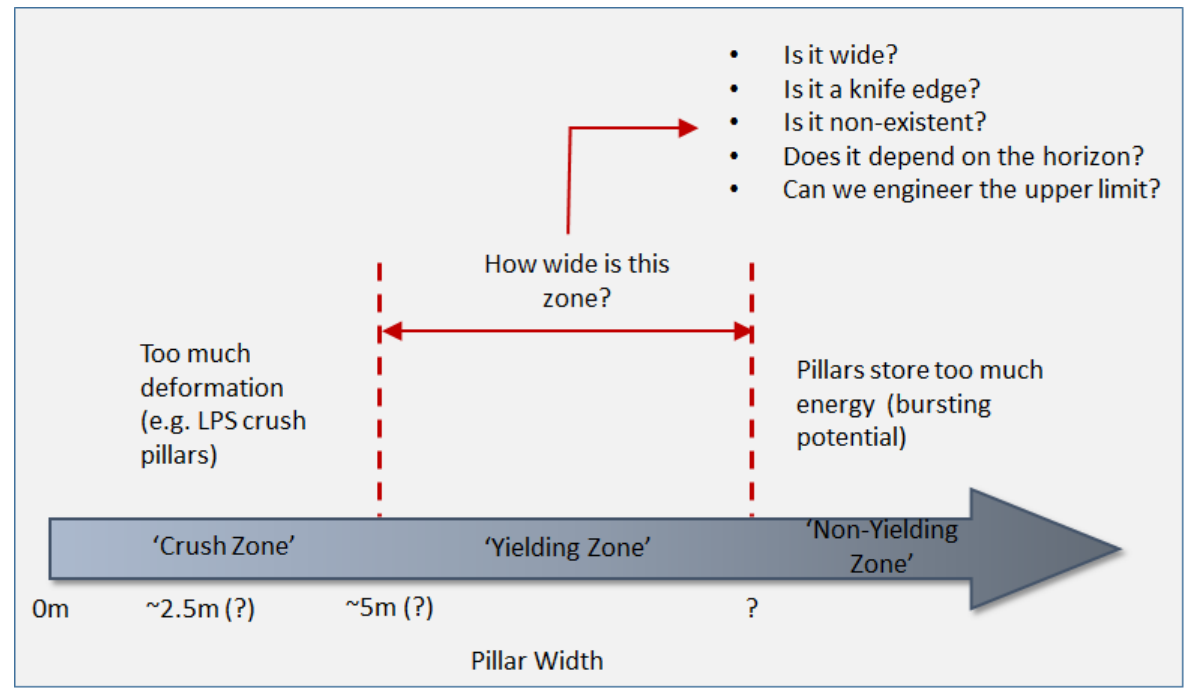

Figure 7. Pillar size vs yielding zone 


\section{Monitoring techniques}

The monitoring techniques included an assessment of internal pillar yielding behaviour through borehole camera monitoring and GPR. Convergence measurements in the adjacent excavations are then assessed for overall closure, yield and the extent of pillar size changes.

\section{Borehole camera monitoring}

Lunder (1994) and Kaiser et al (1996, 2018), Martin (1997) and Esterhuizen et all (2011), all discuss the significance of pillar or sidewall fracturing in relation to the pillar failure process as well as the depth of fracturing in relation to support design. Borehole camera monitoring techniques have been widely applied in the mining industry to determine the extent of damaged rock and detect the location of weak partings in the rock mass.

At the South Deep Mine, the Rock Vision borehole camera (See Figure 8), was used by Sengani and Andrews (2017) to successfully determine the extent of fracturing of $6 \mathrm{~m}$ wide $\times 10 \mathrm{~m}$ long $\times 5.5 \mathrm{~m}$ high in-stope yield pillars as well as assessing the effectiveness of face preconditioning.

The information used in in this paper, comes from the same camera used to assess the depth of fracturing of the $8 \mathrm{~m}$ wide by $20 \mathrm{~m}$ long yield pillars.

\section{Ground penetrating radar}

GPR uses the transmission of electromagnetic waves, in the 10 to $1000 \mathrm{~Hz}$ range into the rock and the reflected pulses. These reflections could be due to boundary interfaces, fractures and or discontinuities, Dong et al (2011). The sub-surface profiler (See Figure 8), a GPR tool supplied by Reutech Mining, was used to complement the borehole camera in assessing the extent of fracturing through the $8 \mathrm{~m}$ wide $\mathrm{x}$ $20 \mathrm{~m}$ long x $5.5 \mathrm{~m}$ high yield pillars. GPR results were calibrated with information from the borehole camera regarding fracturing assessments.
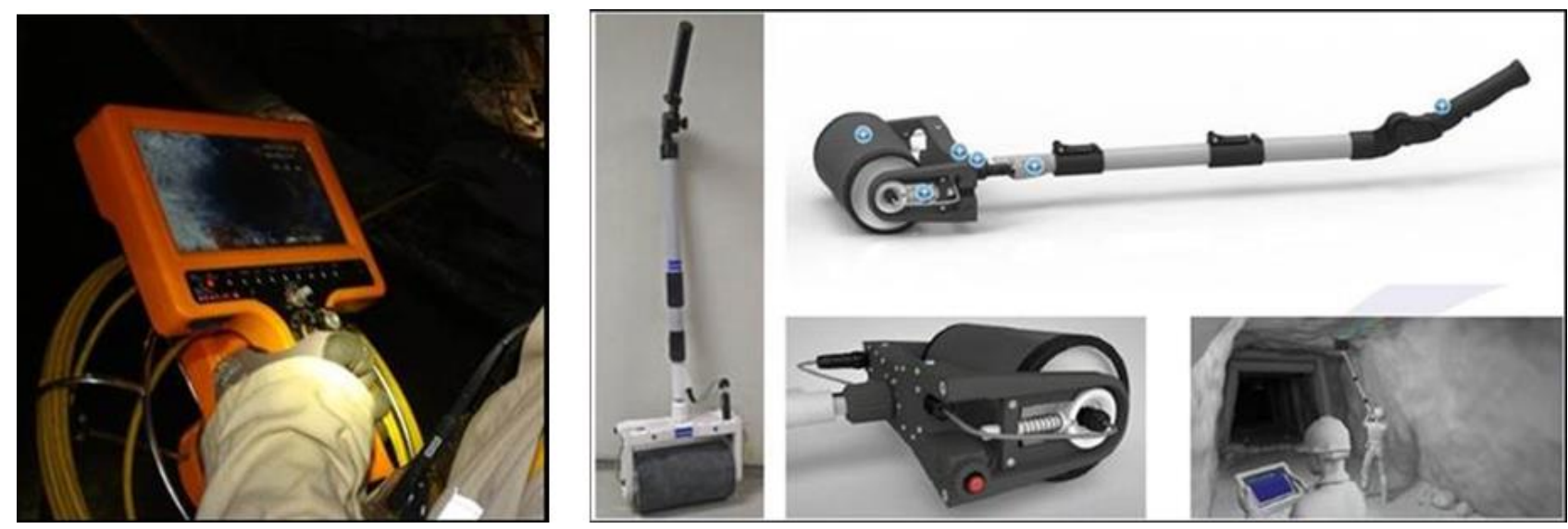

Figure 8. Rock vision borehole camera (left) and sub-surface profiler for GPR assessments (right).

\section{D Laser convergence monitoring}

Historically, underground mining operations have used extensometers and/or instrumented ground support for measuring and monitoring deformation. These techniques, together with survey tools such as a total station, have been instrumental in providing point measurements - the place where instruments are installed. The major shortcomings of such techniques, includes lack of deformation measurements along entire excavation, Jones and Beck (2017), and limited understanding of which region of the excavation has in fact deformed as movement in some cases is relative. The shortcomings at this site have been overcome by using $3 \mathrm{D}$ laser scanning technologies.

Use of 3D laser scanning is not new technology for deformation monitoring on surface mining operations. However, the adoption of mobile 3D laser scanners for deformation monitoring in underground mines is a more recent technology. Jones and Beck (2017) discuss the application of light 
detection and ranging (Lidar) technology to monitor and measure deformation in underground mines by means of comparing superimposed successive full 3D scans. Such results quantitatively provide the magnitude, direction, location and extent of regions undergoing deformation. The deformation results obtained allow timeous allocation of resources to regions where the existing installed ground support has reached its working capacity limits; this is termed Support Planned Maintenance by Kaiser (2018). The deformation results also give an indication of convergence of the cut, which is important for calibration of numerical modelling.

South Deep Mine purchased the Zeb-Revo 3D laser scanner (See Figure 9) in 2018 to conduct convergence monitoring of its destress cuts. This scanner is a handheld unit which captures cloud points at a rate of 43200 points per second at $30 \mathrm{~mm}$ to $300 \mathrm{~mm}$ absolute accuracy (according to the original equipment manufacturer (OEM).

Geo-referencing target spheres were placed and surveyed in the areas were 3D scanning was being conducted. The targets spheres assist with geo-reference transformations of the scanned point clouds during processing. Processing was conducted in-house using Cloud Compare and Trimble Realworks software as supplied by Optron (Pty) Ltd.

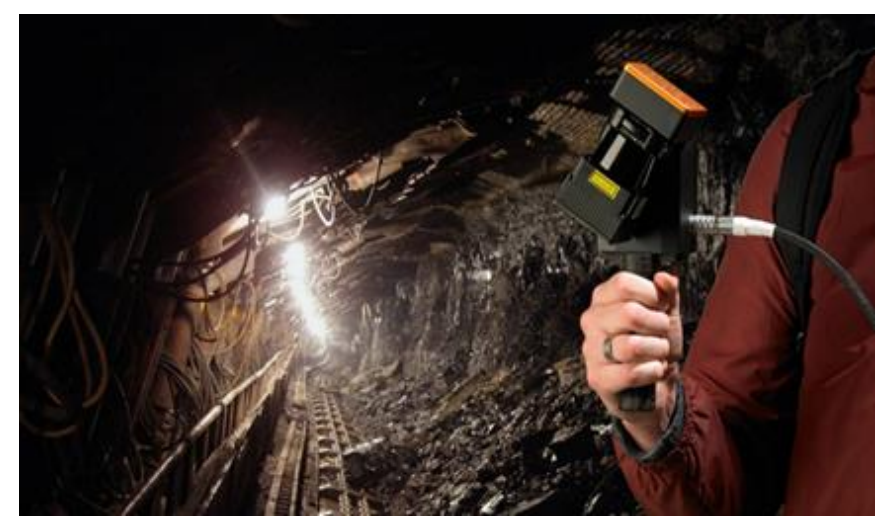

Figure 9. GeoSLAM Zeb-Revo handheld scanner (Image from GeoSLAM Brochure)

\section{Monitoring results}

The monitoring study was conducted in Corridor 1B, 2A and 2B. This corridor started off with $4.5 \mathrm{~m}$ wide $\times 10 \mathrm{~m}$ long pillars which were subsequently increased to $6 \mathrm{~m}$ wide $\times 10 \mathrm{~m}$ long pillars and then most recently $8 \mathrm{~m}$ wide $\times 20 \mathrm{~m}$ long pillars. The pillars assessed had a w:h ratio ranging from 1,7 to 2,4. A summary of the pillars assessed is given in Table I. 
Table I. Summary of the pillars assessed

\begin{tabular}{|c|c|c|c|c|c|c|c|c|}
\hline Pillar ID & Section & $\begin{array}{l}\text { Pillar } \\
\text { length }\end{array}$ & $\begin{array}{l}\text { Pillar } \\
\text { width }\end{array}$ & $\begin{array}{c}\text { We } \\
\text { (Effective } \\
\text { width) }\end{array}$ & $\begin{array}{l}\text { w:h ratio } \\
\text { (Assuming } \\
5,5 \mathrm{mH})\end{array}$ & $\begin{array}{c}\text { Borehole } \\
\text { camera }\end{array}$ & GPR & Yielded? \\
\hline 9 & 100 1BW Cut 3 & 28,9 & 5,5 & 9,2 & 1,7 & & $x$ & Yielded \\
\hline 29 & 100 1BW Cut 3 & 28,3 & 5,2 & 8,8 & 1,6 & & $x$ & Yielded \\
\hline 30 & 100 1BW Cut 3 & 23,5 & 5,9 & 9,4 & 1,7 & $x$ & & Yielded \\
\hline 32 & 100 1BW Cut 3 & 15,3 & 5 & 7,5 & 1,4 & $x$ & & Yielded \\
\hline 34 & 100 1BW Cut 3 & 23,5 & 7,7 & 11,6 & 2,1 & & $x$ & Yielded \\
\hline 1 & 100 2AW Cut 3 & 18,2 & 7 & 10,1 & 1,8 & $x$ & & Yielded \\
\hline 2 & 100 2AW Cut 3 & 19 & 8,2 & 11,5 & 2,1 & $x$ & $x$ & Yielded \\
\hline 3 & 100 2AW Cut 3 & 18 & 7,6 & 10,7 & 1,9 & & $x$ & Yielded \\
\hline 6 & 100 2BW Cut 3 & 20,3 & 10 & 13,4 & 2,4 & $x$ & $x$ & Yielded \\
\hline 12 & 100 2BW Cut 3 & 25 & 7,8 & 11,9 & 2,2 & $x$ & $x$ & Yielded \\
\hline 13 & 101 2BW Cut 3 & 9,7 & 9 & 9,3 & 1,7 & $x$ & $\mathrm{x}$ & $\begin{array}{l}\text { Not fully } \\
\text { yielded, } \\
\text { pillar in } \\
\text { destress } \\
\text { shadow }\end{array}$ \\
\hline
\end{tabular}

\section{Borehole camera monitoring results}

Seven $4 \mathrm{~m}$ long $\times 46 \mathrm{~mm}$ diameter holes were drilled into the pillars in various mining corridors (See Table I), for camera hole inspections. All camera inspections where conducted within 24 hours of the holes being drilled. Fracture frequencies obtained from the borehole cameras were then used to empirically calibrate the GPR radar scan data.

Examples of the borehole camera investigations are given in Figures 10 and Figure 11. Plots of the camera borehole results show that $100 \%$ of $\mathrm{BH} 2, \mathrm{BH} 3$ and $\mathrm{BH} 4$ have fracture frequencies of 20 fractures per metre (0.05 m spacing) or greater. The logs of BH1 and BH5 shows that more than $75 \%$ of each borehole length have fracture frequencies of twenty or greater fractures per metre. The remaining length of $\mathrm{BH} 5$ shows ten fractures or less per metre. This is expected as the pillar lies in the destressed shadow of the cut.

Based on mining experience in South Africa, that a highly-fractured pillar cannot retain sufficient energy to burst, these results confirm yielding of the especially larger $8 \mathrm{~m}$ wide $\times 20 \mathrm{~m}$ long pillars.

All holes were inspected within 24 hours of drilling the holes. Borehole inspections are then reinspected between $48 \mathrm{hrs}$ to $72 \mathrm{hrs}$ later and show further crushing of holes, which is consistent with the continuous yielding state of pillars over time. The high fracture frequencies towards the toe of the holes confirm yielding extending to the core of the pillar, hence low risk of pillar bursting.

\section{GPR results}

GPR assessments were conducted using the sub-surface profiler (SSP) on the same pillars where the borehole camera assessments were conducted. Special attention was paid to running the SSP continuously in the region without the installation of welded mesh, i.e., below the grade line. Running the SSP on welded mesh causes very inaccurate results as the electromagnetic waves deployed by the scanner rebounds from the mesh surface.

Results of the scans on the $8 \mathrm{~m}$ wide $\times 20 \mathrm{~m}$ long pillars in one of the corridors (Corridor 2b), are shown in Figure 10 and Figure 11. When comparing borehole fractures to the intensity and depth of fracturing interpreted from the GPR data, there appears to be a good correlation between the methods. 
Interestingly, minor faults noted in the camera boreholes could also be observed in the GPR scan data. This can be seen in the comparison of the GRP fractured zone to the borehole camera holes BH 1 and BH 2 in Figure 11.
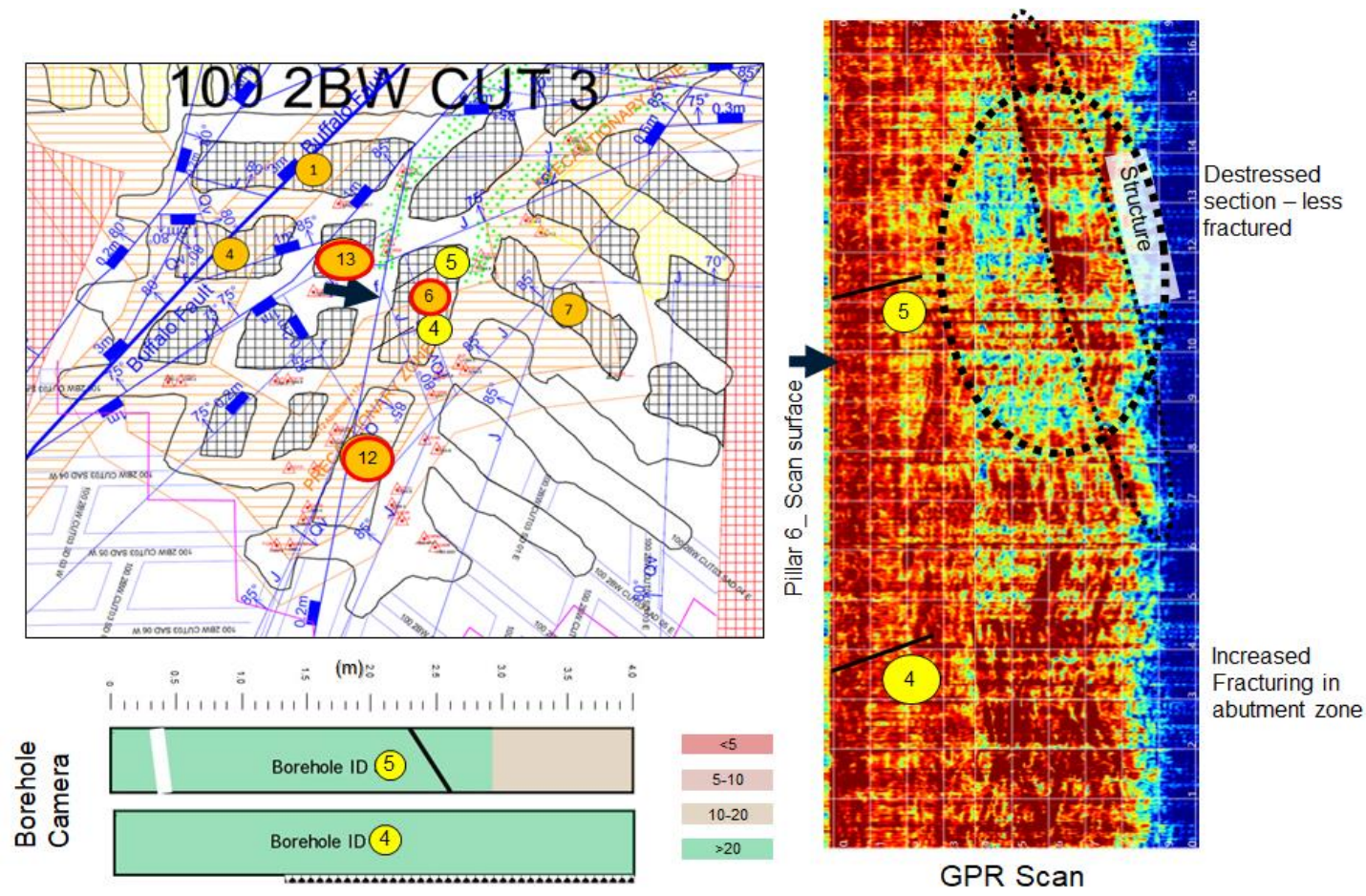

Figure 10. GPR scans and borehole camera results on Pillar 6
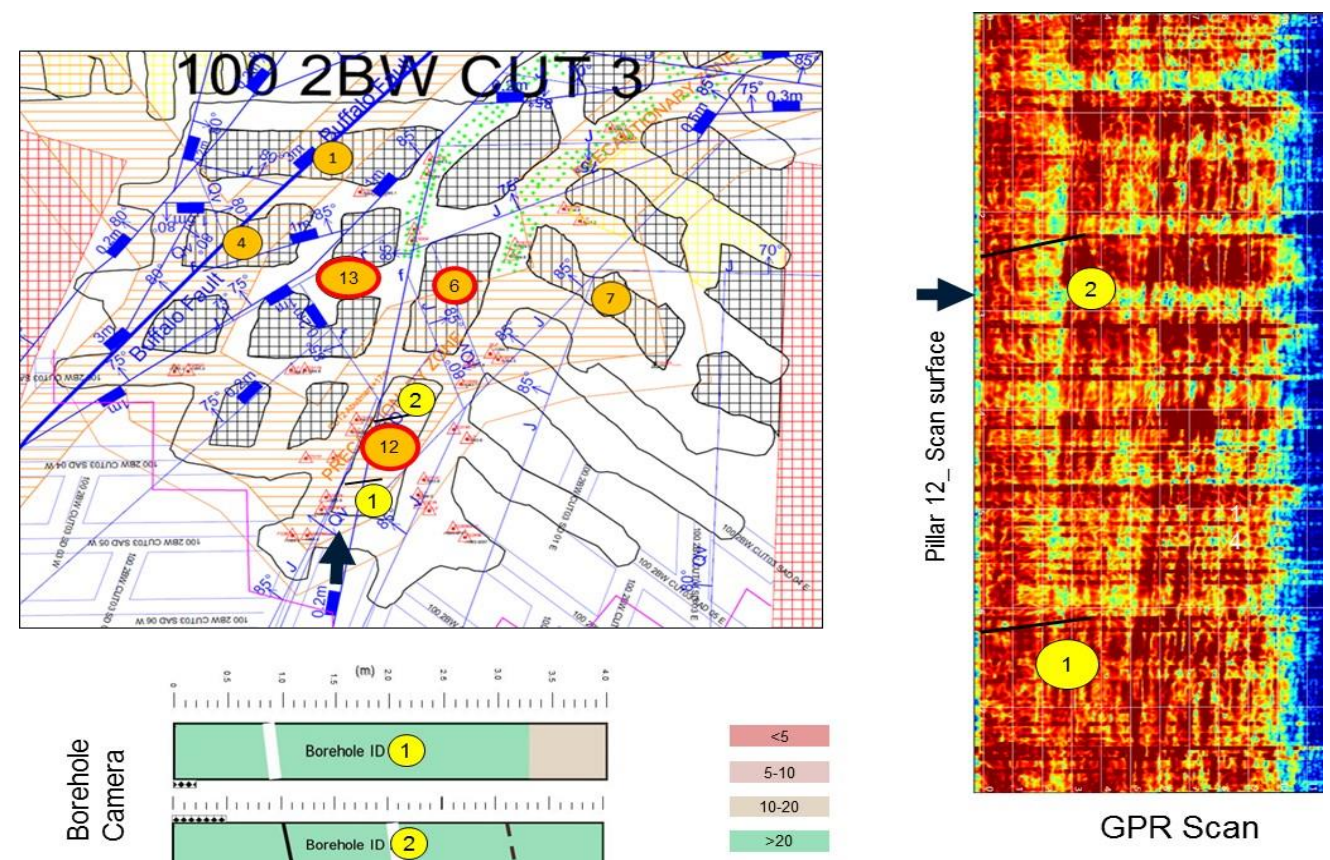

Figure 11. GPR scans and borehole camera results on Pillar 12 
All the pillars, apart from Pillar 13 (See Table I), indicated extensive fracturing to its core. Further work is required to understand pillar behaviour when they are mined under destressed (low stress) conditions behind the face of the cut (see above), as was the case for Pillar 13.

\section{D laser convergence monitoring results}

Two laser convergence data sets were collected. Point clouds from scans done in June 2018 were compared to scans done in December 2018 in 100 2BW Cut 3.

No baseline scan was conducted in late 2017 when the cut started. Therefore, because the first scan was conducted 6 months after the cut began, it was expected that some deformation had already occurred. It is difficult to determine the total amount of deformation over the life of the cut since the laser scan only represents deformation over a 6-month time frame.

Figure 12 shows the net cloud density for areas which had undergone displacement from $0 \mathrm{~mm}$ to 50 $\mathrm{mm}$, from $51 \mathrm{~mm}$ to $100 \mathrm{~mm}$ and from $101 \mathrm{~mm}$ to $200 \mathrm{~mm}$ (from left to right respectively). The convergence scanning data indicates that the whole cut had undergone at least $100 \mathrm{~m}$ of deformation with up to $200 \mathrm{~mm}$ of deformation observed in the excavations directly below the overlying cut's abutment zone.

As the deformation is plastic, there was no need to compare the results to elastic modelling results. Also, as scans are not being done at the start of mining (and any potential deformation not picked up), and the short time frame between scans, the results were not compared to inelastic modelling results.

Historic ground support standards were installed to the gradeline and did not cater or manage to inhibit pillar scaling. From the laser scanning data, a significant amount of spalling below the gradeline can be observed. This is consistent with scaling of the yielding pillars observed underground where the ground support is not installed to the footwall. The bottom $1 \mathrm{~m}$ is not supported and therefore permits escape of scaled material. Figure 13 shows the perspective view of excavation displacement in $1002 \mathrm{BW}$ Cut 3.

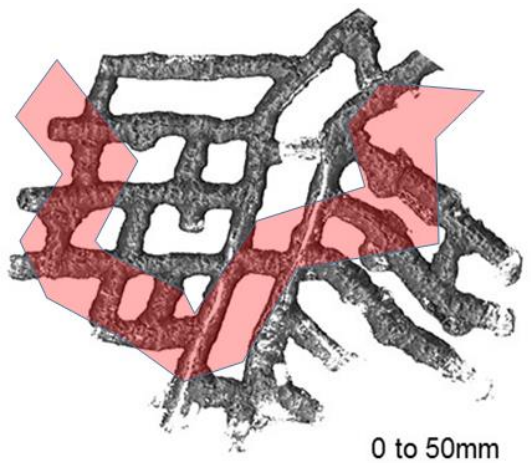

0 to $50 \mathrm{~mm}$

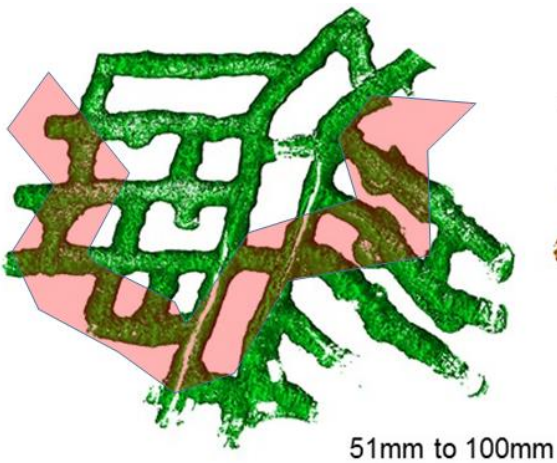

$51 \mathrm{~mm}$ to $100 \mathrm{~mm}$

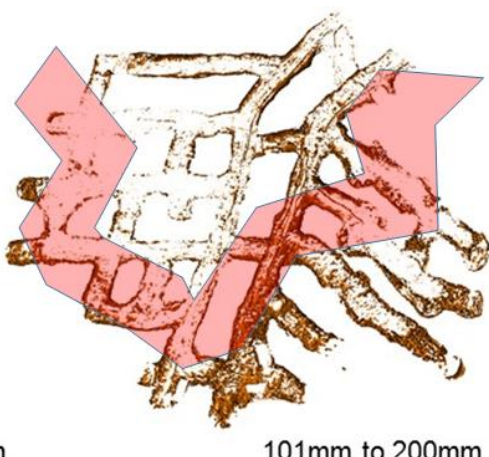

$101 \mathrm{~mm}$ to $200 \mathrm{~mm}$

Abutment from the overlying cut

Figure 12. June 2018 vs December 2018 displacement 100 2BW Cut 3 


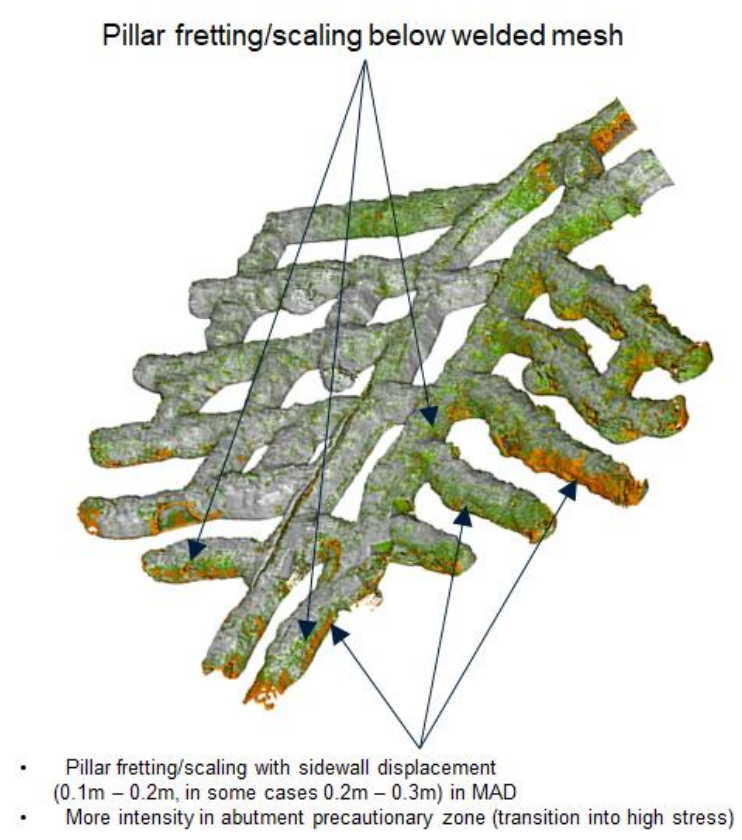

Figure 13. 3D isometric view showing high deformation below the grade line

\section{Discussion of results}

As can be seen from the results presented above, the borehole camera assessments were successfully used to calibrate GPR results and in this case indicated that most of the pillars have extensively fractured to their core.

\section{Pillar stability}

To compare pillar stability at South Deep to other pillar classification schemes, the width to height ratios of several $8 \mathrm{~m}$ wide $\times 20 \mathrm{~m}$ long $\times 5.5 \mathrm{~m}$ high pillars were plotted against pillar stress (calculated from numerical modelling) divided by Sigma c (UCS of intact rock) as shown in Figure 15, Martin and Maybe (2000). The data fits into width to height ratio (w:h ratio) range of between 1.3 to 2.5 with the concentration range falling between 1.6 and 2.1.

According to Potvin (2018), the South Deep data fits the Lunder and Pakalnis (1997) curve which relies on defined classes of failure (See Figure 15 by Lunder (1994). This curve sees the pillar failure as a continuum rather than a stable/failed boundary at a factor of safety of 1 .

Based on Figure 14, the South Deep data falls at the upper limit of Class 4 and lower limit of Class 5 in the pillar stability classification which shows optimal yielding and fracturing through the pillars. This finding is consistent with the findings from the numerical modelling and underground investigations; borehole camera, GPR and convergence investigations. 


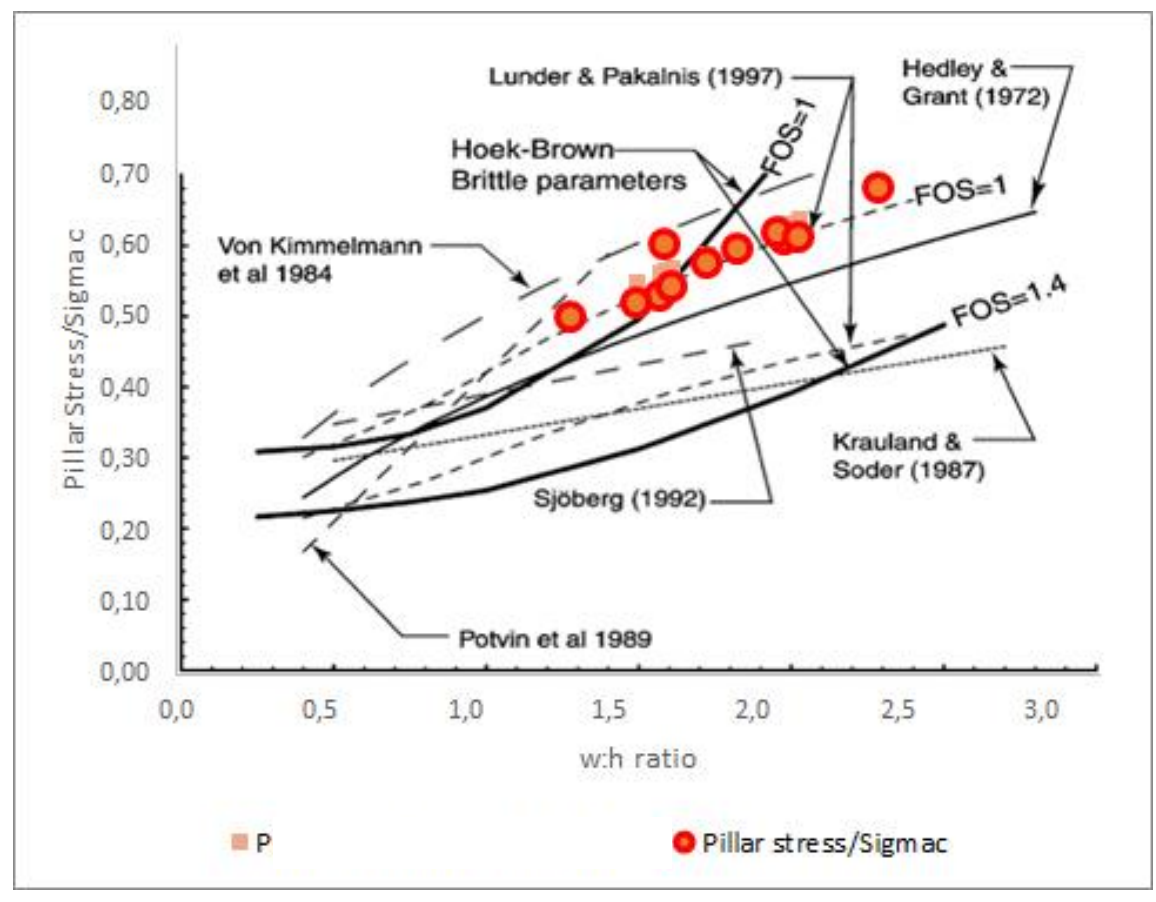

Figure 14. Pillar w:h ratio os pillar stress/UCS.

\section{Laser convergence and ground support}

Laser convergence scanning data indicated convergence did occur in the cuts however, as no baseline scan for this cut was done the total displacement cannot be accurately ascertained. Baseline surveys will be conducted for all new excavations going forward.

Laser scanning data was found to match underground observations and indicated that extensive spalling took place below the support level. Based on these results, it was determined that the pillars require support to the footwall to ensure their long-term integrity. Historically, ground support was installed across the backs and down the sidewalls to the gradeline ( $1.0 \mathrm{~m}$ to $1.5 \mathrm{~m}$ above floor level). This did not prevent pillar spalling. From the laser scanning data, a significant amount of spalling below the gradeline was observed (See Figure 13). This measure depth of spalling is consistent with underground observations below the gradeline. The bottom $1 \mathrm{~m}$ was not confined and therefore permitted escape of fractured material. Figure 13 shows the perspective view of excavation displacement in 100 2BW Cut 3.

To achieve confinement, fibrecrete from the shoulders to the floor was introduced into the primary support cycle. 


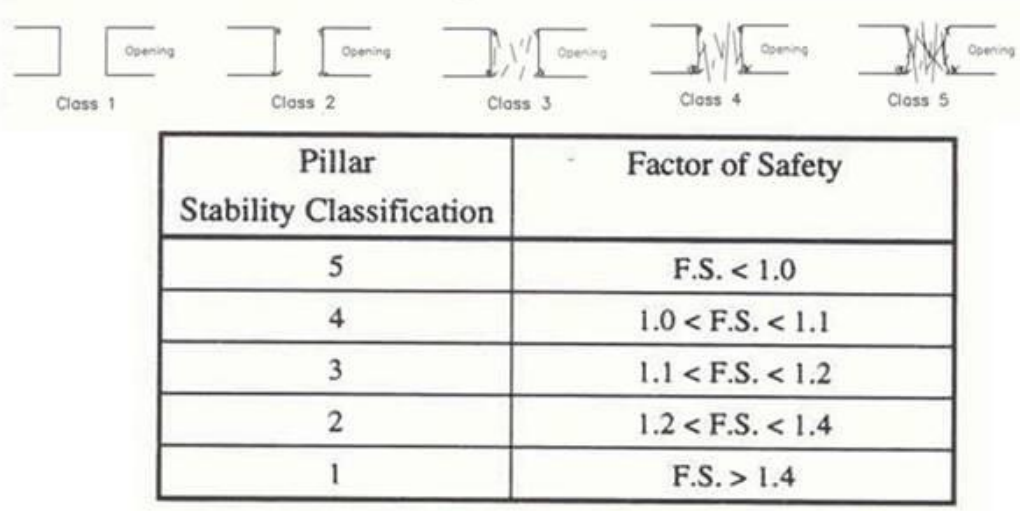

Figure 15. Pillar stability classification, Lunder (1994)

Early numerical modelling results indicated that increasing the pillar width to $10 \mathrm{~m}$ wide pillars may tip the pillar behaviour from a yielding pillar to a rigid pillar, running the risk of potential pillar bursting problems. Further work using the observational and monitoring approach is required to determine the best pillar size for South Deep. However, larger pillars may not be a necessary consideration for South Deep destress pillars at this stage.

\section{CONCLUSIONS}

South Deep has combined numerical modelling with the observational approach and is refining the yield pillar design. The use of borehole cameras, ground penetrating radar, and laser convergence monitoring, are all part of the observational approach which in turn, can be used to further calibrate numerical models.

Using this method has allowed South Deep to successfully increase pillars from $6 \mathrm{~m}$ wide by $10 \mathrm{~m}$ long $8 \mathrm{~m}$ wide by $20 \mathrm{~m}$ long without increasing the seismic risk at the operation. This methodology will form the basis of all pillar assessments in the future. The design should be continually reviewed for performance and suitability especially when long hole stoping commences.

A significant amount of work still needs to be done to determine the final optimal pillar layout and to understand individual pillar performance at South Deep. The monitoring methods employed at South Deep have been successfully used to complement each other in providing critical information on the performance of the pillars.

\section{REFERENCES}

Andrews, P. (2017). The Highs and Lows of Gold Fields Monitoring Experiences. Developments in Rock Stress Measurements and Monitoring Seminar.

Hedley, D.G.F., and Grant, F. (1972). "Stope and pillar design for the Elliot lake uranium mines," Can. Inst. Min. Metall. Bull, Vol. 65, pp. 37-44.

Hoek, E. and Brown, E.T. (1980). Underground Excavations in Rock, Inst. Min. Metall., London.

Jager, A.J and Ryder J.A. (1999). A Handbook on Rock Engineering Practice for Tabular Hard Rock Mines. The Safety in Mines Research Advisory Committee (SIMRAC) Publications. 
Jones, E. and Beck, D. (2017). The use of three-dimensional laser scanning for deformation monitoring in underground mines. Proceedings of the $13^{\text {th }}$ AusIMM Underground Operators Conference: Paper No. 066 pp. 267-270.

Joughin et al (2011). Mining methods and backfill at South Deep Gold Mine. W.C. JOUGHIN*, W.M. BESTER† and M. DU PLOOY† *SRK Consulting, South Africa. South Deep Gold Mine, South Africa.

Kaiser, P.K. McCreath, D.R and Tannant, D.D. (1996). The Canadian Rockburst. Canada

Kaiser, P.K. et al (2018). The Canadian Rockburst. Canada

Krauland, N. and Soder, P.E. (1987). "Determining pillar strength from pillar failure observations," Eng. Min. Journal, Vol. 8, pp. 34-40.

Lilley, C. (2014). “Assessment of Stoping Methods for South Deep”. Internal report by Beck Engineering.

Lilley, C. (2016). “Assessment of alternative yield pillar layouts for South Deep". Internal report by Beck Engineering.

Lunder, P.J. (1994) "Hard Rock Pillar Strength Estimation an Applied Approach," MASc. Thesis, Dept. Mining and Mineral Process Engineering, University of British Columbia.

Lunder, P.J. and Pakalnis, R. (1997). "Determining the strength of hard rock mine pillars," Bull. Can. Inst. Min. Metall., Vol. 90, pp. 51-55.

Martin, C.D. and Maybee, W.G. (2000). "The strength of hard rock pillars," Int. Jnl. Rock Mechanics and Min. Sci., Vol. 37, pp. 1239-1246.

Ozbay, M.U., Ryder, J.A and Jager, A.J. (1995). The design of pillar systems as practised in shallow hardrock tabular mines in South Africa. The Journal of The South African Institute of Mining and Metallurgy, vol. 84, no. 8, pp. $7-18$.

Potvin, Y, Hudyma, M., and Miller, H.D.S. (1989). "Rib pillar design in open stoping," Can. Inst. Min. Metall. Bull. Vol. 82, pp. 31-36.

Potvin, Y. (2018) Personal Communication.

Ryder, J.A and Jager, A.J. (2002). A text book on Rock Mechanics for tabular hard rock mines. Johannesburg, South Africa: The Safety in Mines Research Advisory Committee (SIMRAC); in conjunction with CSIR Division of Mining Technology.

Sjoberg, J. (1992a). Failure modes and pillar behaviour in the Zinkgruvan mine. Rock Mechanics. Lulea University, Department of Mining Engineering. Rotterdam: Balkemia.

Sjoberg, J. (1992b). Stability and Design of Stope Roofs and Sill Pillars in Cut and Fill and Open Stope Mining with Application to Zinkgruvan Mines. Licentiate Thesis, Lulea University of Technology, Lulea, Sweden.

Von Kimmelman, M.R., Hyde, B. and Madgwick, R.J. (1984). "The use of computer applications at BCL Limited in planning pillar extraction and the design of mining layouts," In Design and Performance of Underground Excavations, Int. Soc. Rock Mech. Symposium, Brown and Hudson, eds., Brit. Geotech. Soc., London, pp. 53-63. 
Y. Dong, F. Ansari, in Service Life Estimation and Extension of Civil Engineering Structures (2011).

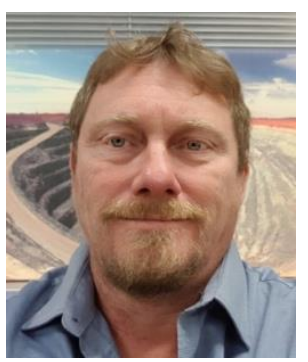

\section{Peter Andrews}

Vice President and Group Head of Geotechnical Gold Fields

Peter has over 20 years of experience in the mining industry in both operating and consulting capacities. He has a broad range of experience with specific expertise in underground rock mechanics in the geotechnical engineering field. Over this period, he has obtained international industry experience, having worked on a number of large underground operations in Australia, New Guinea, South Africa, and South America. He specialises in underground stability analysis, extraction sequencing and ground support. 
